hydrogen and of effectively removing the residual oxygen from a cell and its contents.

Measurements on the electromotive force of cadmium amalgams at $25^{\circ}$, extending from the saturated amalgam to a dilution of one part of cadmium in one hundred million of mercury. These observations were all based on a constant reproducible electrode and the values for amalgams in different cells are therefore directly comparable.

The discovery of a region between one gram of cadmium to 100 of mercury, and one gram of cadmium to one million of mercury, where the potential of any two amalgams corresponded to the requirements of the gas laws. A deviation from these requirements was found for amalgams containing less than one gram of cadmium to one million of mercury. This deviation was anticipated and is interpreted as evidence in favor of the reversibility of the reduction of mercury by cadmium, indicating that this reaction does not go to completion but that a definite equilibrium is established.

PRINCETON UNIVERSITY,

September, 1908.

\title{
THE MIXED BARIUM-STRONTIUM CHROMATE PRECIPITATE.
}

By L. H. Duschak.

Received September 28, I908.

\section{Introduction.}

A study of the so-called occlusion of barium chloride by precipitated barium sulphate, carried out by G. A. Hulett and the author, ${ }^{1}$ served as the starting point for the work now under consideration. In the first paper it was suggested that the presence of barium chloride as well as hydrochloric acirl and water in the barium sulphate could most easily be explained by regarding the precipitate as an isomorphous mixture of barium sulphate with one or more complex salts of barium. It was stated further ${ }^{1}$ (p. 217 ) that cases of isomorphism in which one component, owing to its ready solubility, was present in only a minute quantity were probably more common than one might at first suppose; and that many irregularities encountered in analysis might find their explanation in this circumstance.

The mixed barium sulphate precipitate which we studied belongs to one of the two general classes of simple isomorphous mixtures, namely, that mixture which contains several salts of the same metal. To the other class belong those mixtures containing two or more metals combined with the same acid radicle.

The mixed precipitate of barium and strontium chromates which is formed as an intermediate product in the separation of barium and stron-

${ }^{1} Z$. anorg. Chem., 40, 196 (1904). 
tium by the well-known Fresenius ${ }^{2}$ method suggested itself as a faniliar example of this second class of simple isomorphous mixtures and from this standpoint a study of the mixed precipitate was undertaken.

\section{Preparation of Materials.}

Chromic Acid.-All commercial chromic anhydride was found to contain sulphuric acid, so pure chrotnic acid was prepared by the electrolysis of a saturated solution of recrystallized potassium dichromate. The electrolyte was contained in al large glass dish with solid salt upon a shelf within to maintain saturation. The platinum electrodes were both enclosed in porous cups. In the beginning clistilled water was placed in the anode cup and a supply arranged so that during the electrolysis the level of the liquid in this cup remained about I cm. above that without. Constant-level siphons removed liquid from the large dish and from the cathode compartment. With a current of 3 amp, it was found necessary to use a cooling coil in the electrolyte. The solution obtained from this process contained about $76 \mathrm{~g}$. $\mathrm{H}_{2}(\mathrm{Cr})_{4}$ per liter and spectroscopic examination showed it to be free from potassium.

Barium Actatc,--A freshly prepared solution of recrystallized barium hydroxide was exactly neutralized with pure acetic acid and diluted

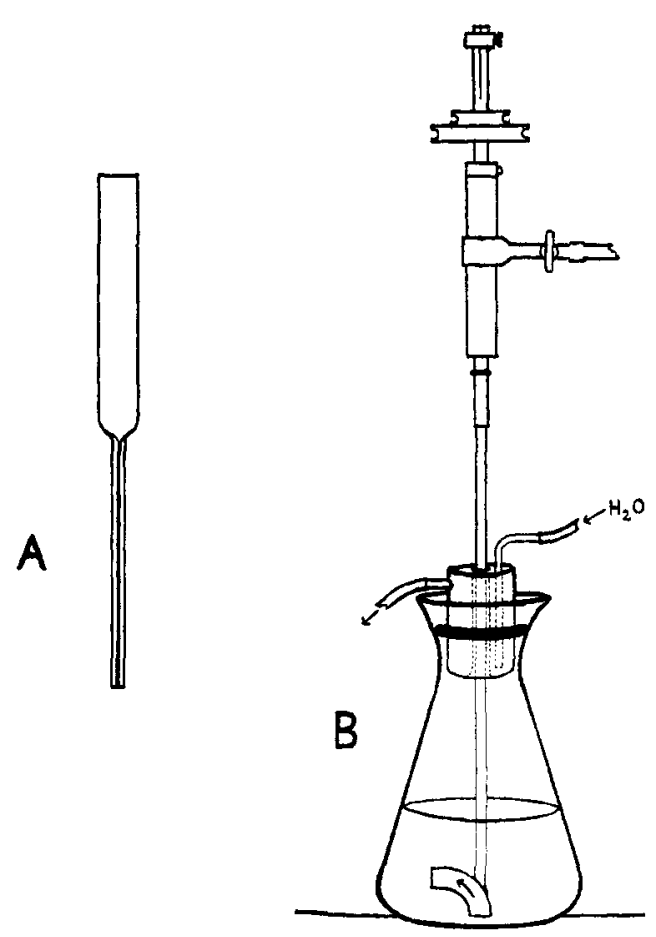
to contain I/ Io formula weight per liter. A rery minute excess of acetic acid was added and the concentration of the solution accurately determined by precipitating the barium as sulphate.

Strontium chromate was prepared from recrystallized strontium chloride and recrystallized ammonium chromate. $A$ few drops of acetic acid were added to the strontium chioricle solution and enough ammoniun chromate solution to produce a slight precipitate. This was allowed to settle, the clear liquid decanted and the operation repeated. This procedure removed any traces of barium present in the strontium walt. The clear solutions of strontium chloride and an.

${ }^{2}$ R. Fresenius, Z. analyt. Chom., 29, 413 (1890). 
monium chromate were then allowed to flow very slowly from dropping tubes* (A, Fig.) into a large volume of boiling distilled water which was stirred mechanically. The strontium chromate so formed was very coarse-grained and a microscopic examination showed it to be a beautifully crystalline preparation.

\section{Experimental Part.}

In the first experiments it was purposed to form the barium chromate precipitate in a solution containing a definite and unvarying concentration of strontium chromate and acetic acid. To this end several hundred cc. of a given solution of these substances were placed in a Phillips' beaker on a steam bath and mechanically stirred. A carefully measured volume of standard barium acetate solution (usually $20 \mathrm{cc}$.) and an equal volume of "correcting solution" were allowed to flow simultaneously from dropping tubes down opposite sides of the beaker. These dropping tubes delivered $20 \mathrm{cc}$. in about $8 \mathrm{~min}$. The "correcting solution" contained strontium chromate, chromic acid and acetic acid in such quantities that it exactly compensated for the changes in volume incident to the addition. Barium chromate is slightly soluble in dilute acetic acid even when some chromate is present. As is well known, when a substance precipitates from a solution in which it is slightly soluble, relatively few crystal nuclei are formed and the precipitate is therefore very coarse-grained. This was true in the case of the barium chromate, which was distinctly crystalline and if the stirring was stopped for a moment the precipitate at once dropped to the bottom.

Evaporation was prevented by a special form of condenser in the neck of the beaker ( $B$, Fig.). After from I to 3 days' stirring, the precipitate was filtered on asbestos in a Gooch crucible, washed with cold water and weighed after drying at $120^{\circ}$. The difference between this weight and the theoretical weight of barium chromate gave approximately the weight of strontium chromate retained by the precipitate. In these and subsequent experiments a small correction arising from the slight solubility of barium chromate in the solution should be introduced to make the result quantitatively accurate.

In some experiments the precipitate was dissolved in dilute hydrochloric acid, potassium iodide solution added and the free iodine titrated with standard thiosulphate solution. The results of this titration together with the mass of the precipitate furnished the data necessary for the computation of the amounts of barium chromate and strontium chromate present. This indirect method, however, offered no advantages over the direct one and served only as a check.

The results of this first series of experiments follows:

* These dropping tubes were first used in the work on barium sulphate and chloride. See nage 202 of that article. 
Composition of solution.

\begin{tabular}{|c|c|}
\hline $\begin{array}{l}\text { Vol, containing } \\
\text { i mole Srero }\end{array}$ & $\begin{array}{l}\text { Vol, containing } \\
\text { tmole } \mathrm{HC}_{2} \mathrm{H}_{2} \text {. }\end{array}$ \\
\hline to 1 & $121 .(0) .5 \%$ \\
\hline to 1 & $121 .(0.5 \%)$ \\
\hline +01. & $121 .(0.5 \%)$ \\
\hline 401. & $121 .(0.5 \%)$ \\
\hline 801 & $2+1 .(0.25 \%)$ \\
\hline 801 & $2+1 .(0.25 \%)$ \\
\hline 1601 & $481 .(0.13 \%)$ \\
\hline 1601 & $4^{81 .(0.13 \%)}$ \\
\hline
\end{tabular}

T.IBLF: I

\begin{tabular}{|c|c|c|}
\hline Mass of precipitate. & $\begin{array}{l}\text { Mass SrCrO } \\
\text { in ppt. }\end{array}$ & $\begin{array}{c}\text { Ratio } \\
\mathrm{SrCrO}\end{array}$ \\
\hline $0.582+8$. & 0.08178. & $0.20,3$ \\
\hline (). $5930 \mathrm{~g}$. & $0.0923 \mathrm{~g}$. & 0.229 \\
\hline (). $5967 \mathrm{~g}$ & $0.0000 \mathrm{~g}$. & 0.239 \\
\hline $0.594 \mathrm{Ig}$ & $0.003+3$. & 0.2 .32 \\
\hline $0.5478 \mathrm{~g}$ & $0.0+71$. & 0.117 \\
\hline $0.5+63 \mathrm{~g}$. & $0.0456 \mathrm{~s}$. & 0.113 \\
\hline $0.5166 \mathrm{~g}$. & $0.0159 \mathrm{~g}$. & 0.040 \\
\hline $0.5135 s$. & $0.0128 \mathrm{~g}$. & 0.03 .3 \\
\hline
\end{tabular}

The results show that an approximately constant relation exists in each case between the concentration of the strontium chronate in solution and the amount retained by the precipitate. A microscopic examination of several precipitates showed them to be composed of well formed crystal grains varying in size from 2-30 microns. In every case the precipitate was so coarse-grained that its solubility had reached the normal mininum value. Regarding it as an impurity, the relatively large amount of strontium chromate retained by the barium chromate is to be attributed to the fact that the chromates do not have the widely varying solubility which is found in the case of barium chloride and barium sulphate, for example.

Turning now to a consideration of the exact nature of the mixed precipitate, Küster ${ }^{3}$ believes that diffusion takes place in solid solution but not in isomorphous mixtures. Accepting this distinction it becomes important to determine whether or not the strontinm chromate can diffuse through the barium chromate crystals. This point was tested by the following experiments.

A dilute solution containing two millimoles of bariun acetate was mixed with an equivalent anount of chromic acid solution in the cold and the liguid containing the finely divided precipitate added to a solution of strontium chronate in acetic acid. The final volume was 200 ce. and the concentrations were, strontium chromate 0.025 molecular, acetic acid 0.08 molecular. The precipitate was stirred on the steam bath in contact with the solution, gradually becoming coarse-grained, and at the end of 4 days it was collected and weighed. The bariun chromate weighing about $0.5 \mathrm{~g}$. had taken up o.or6 $\mathrm{g}$. of strontium chromate. When a finely divided precipitate is stirred in contact with its saturated solution the smallest particles dissolve and the material reprecipitates upon the larger grains." "lis reprecipitation is essentially the same as the direct formil. tion of the barium chromate precipitate and it is therefore not surprising that some mixed chromate was formed in this experiment. The presence

"Küister, \%. phyik. Chem., 17, 367 (1805).

"Hulett, Ibid., 37, 400 (I001). 
of part or all of the strontium chromate in the precipitate can also be explained by diffusion.

A similar experiment was performed with coarse-grained barium chromate formed by the slow interaction of dilute solutions of barium acetate and chromic acid. $1.0009 \mathrm{~g}$. of this preparation were placed in $200 \mathrm{cc}$. of 0.025 molecular strontium chromate solution (0.12 per cent. acetic acid) in a Phillips' beaker fitted with centrifugal stirrer and condenser, and agitated in contact with the solution on the steam bath. At the end of I7 days the precipitate weighed I.0II5 g., a gain of $0.0106 \mathrm{~g}$., and some barium chromate remained behind in solution.

This experiment was repeated with greater care. Barium chromate was prepared by allowing dilute solutions of chromic acid and recrystallized barium hydroxide to flow very slowly from dropping tubes down the separate tubes of a double-tubed reflux condenser into a large volume of boiling distilled water in a Jena flask. The chromic acid solution was started slightly in advance and remained in slight excess throughout the precipitation. The use of the double reflux condenser diluted the solutions largely before reaction, resulting in the formation of a very coarsegrained precipitate. The barium chromate was separated into several grades of different sized particles and the coarsest, averaging ro microns in diameter, used for the experiment.

Two portions, I.0008 g. and I.0002 g. respectively, were placed each in 200 cc. of a 0.05 molecular strontium chromate solution (in I per cent. acetic acid) and stirred on the steam bath as before. After 30 days the precipitates were collected and weighed. The results follow:

\section{I.0449 g., gain $0.044 \mathrm{I}$ g. \\ II. I.0339 g., gain $0.0337 \mathrm{~g}$.}

A portion of precipitate I was analyzed asfollows: $0.217 \mathrm{I} g$. was dissolved in dilute hydrochloric acid and the barium precipitated as barium chromate by the addition of ammonium chromate and anmonium acetate, and after the reduction of the chromate,* the strontium was determined in the filtrate as strontium sulphate. The analysis yielded $0.2064 \mathrm{~g}$. barium chromate and strontium sulphate, corresponding to $0.0087 \mathrm{~g}$. of strontium chromate, a total of $0.215 \mathrm{I}$ g. ( $2 \mathrm{mg}$. less than the sample). The strontium sulphate gave a clear strontium flame with no indication of barium, but the method of analysis was only approximate and no doubt each precipitate was contaminated by a trace of the other metal. Calculated from this analysis, the entire mass of precipitate contained $0.042 \mathrm{~g}$. strontium chromate, agreeing well with the directly observed gain of $0.044 \mathrm{~g}$.

It is thus proved that pure coarsely crystalline barium chromate will take up strontium chromate from solution. One explanation of the

* If $\mathrm{SO}_{4}{ }^{\prime \prime}$ is added to a solution containing $\mathrm{Sr}^{++}$and $\mathrm{CrO}_{4}$ " a mixed precipitate of strontium sulphate and chromate is formed. 
phenomenon may be derived by making two assumptions: First, that in spite of the coarseness of the harium chromate used, dissolving of the small particles and reprecipitation on the large ones took place to an appreciable extent, due perhaps to the smaller particles in the material or to fragnents broken off from large ones by the stirring. This exchange must result in the formation of a small amount of the mixed chromate precipitate. If now a second and allowable assumption be made that the solution pressure of barium chromate from the mixed precipitate is less than that of pure harium chromate it is easy to see that, in contact with the mixed precipitate and strontium chronate solution, the pure barium chromate would dissolve and reprecipitate in the less soluble phase. 'The alternative explanation and simpler one as well, is found by assiming the diffusion of the strontium chromate into the barium chromate.

Thus while these experiments establish diffusion as a possible explanation of the passage of strontium chromate into the precipitate, they do not prove it as a necessity.

Attention was next directed to the reverse process, namely the escape of strontium chromate from the mixed precipitate. Material for this study was prepared by slowly adding dilute barium acetate solution and a "correcting solution" to a large volume of boiling 0.025 molecular strontium chromate solution as in the first series of experiments. The precipitate was very coarse-grained and contained about $45 \mathrm{mg}$. strontium chromate to each millinole of barium chromate. 'The smaller particles were temoved by decantation and the coarsest used for the following experiment. $2.0027 \mathrm{~g}$. were placed in $200 \mathrm{cc}$. of distilled water on the steam bath as usual. At the end of $\mathrm{I}_{5}$ days' stirring the solution had become distinctly yellow and the precipitate weighed $1.9756 \mathrm{~g}$., a loss of $0.027 \mathrm{I} \mathrm{g}$. The filtrate was evaporated to a small volume, the chromate reduced and sulphuric acid and alcohol added. The solution yielded a precipitate weighing $27.4 \mathrm{mg}$. It was slightly colored by chromium from the reduced chromate and no doubt also contained some silica, which accounts for the weight in excess of that corresponding to the loss of weight of the mixed precipitate. The precipitate gave a brilliant strontium flame with no indication of barium; howerer, it must have contained a small amount corresponciing to the solubility of barium chromate in water at $95^{-100^{\circ}}$.

This experiment proves that the strontium chromate can escape from the mixed precipitate. While other explanations may be proposed, this fact established a strong probability of the existence of diffusion, a conclusion which is well in accord with the previous experimental results. Therefore, according to the distinction laid down by Küster (p. 1830) the mixed chromate precipitate is to be regarded as a solid solution of strontium chromate in barium chromate. 
This mixed crystal was selected for study on the supposition that it was a simple isomorphous mixture and, aside from the apparent existence of diffusion, it possesses the typical and characteristic properties of such a mixture. This makes the case one of considerable interest. If the proof of diffusion be accepted as conclusive, the question is at once raised whether diffusion does not exist to a greater or less degree in many socalled isomorphous mixtures. Or, put in another way, is it possible to draw a sharp line between solid solutions and isomorphous mixtures?

The results of this investigation possess interest from an analytical standpoint. R. Fresenius, ${ }^{5}$ who made a thorough study of the chromate method for the separation of barium and strontium, showed that accurate results could not be obtained by a single precipitation of barium as chromate and that the apparent accuracy of the method in the hands of some investigators was due to compensating errors. He proved, however, that an entirely satisfactory separation could be accomplished by a double precipitation of the barium as chromate. The foregoing results fully confirm this first conclusion and, further, show that the explanation of the facts which Fresenius observed is to be found in the existence of a mixed chromate precipitate of definite composition in equilibrium with a saturated barium chromate solution containing a given concentration of strontium chromate. Moreover this condition makes it improbable that a complete separation of the metals is accomplished by a double precipitation. The fact that such procedure has proved satisfactory for analytical purposes shows only that, under the conditions of analysis, the variation produced by mixed precipitate formation is within the experimental error of the method.

\section{Summary.}

A mixed barium-strontium chromate precipitate crystalline and of definite composition is formed in a saturated solution of barium chronate containing given concentrations of strontium chromate and acetic acid.

Diffusion takes place within this substance and it is therefore either to be regarded as a solid solution or diffusion is to be recognized as a possible property of isomorphous mixtures.

This investigation was carried out some time ago in the laboratory of physical chemistry of the University of Michigan. I desire to express my indebtedness to Prof. G. A. Hulett, then of this University, for the suggestion of the problem and for helpful advice during its elaboration.

ANN ARBOR, MICHIGAN, A ugust, 1908 .

¿Z. analyt. Chem., 29, 4I3. 